\title{
A KNOWLEDGE MANAGEMENT MODEL TO IMPROVE THE DEVELOPMENT OF BUSHFIRE COMMUNICATION PRODUCTS
}

\author{
Keith Koon Teng Toh \\ RMIT University \\ keith.toh@rmit.edu.au \\ Brian Corbitt \\ RMIT University \\ Jenine Beekhuyzen \\ Griffith University
}

\begin{abstract}
This paper brings together two bodies of literature around knowledge management (KM) as enterprise integration (EI) and organisational ontology and epistemology as philosophy, in order to develop an extended KM approach to the development of bushfire preparedness material in the Australian context. Knowledge Management (KM) in enterprise integration (EI) practice manifests as process-centric electronic document and records management solutions. Knowledge creation and organisational epistemology is viewed as a social process, but this is often left unrepresented by KM processes. The body of literature on KM tends to focus on organisational functionality and organisational $\mathrm{KM}$ that is based on EI ontology tends to be restricted by organisational functionality and process models. We argue that developing the KM-Model using subjectivist epistemology has a significant role in KM and organisational studies for emergency and disaster agencies. As part of the Bushfire Cooperative Research Centre (CRC) 'Effective Communication and Communities' project, bushfire communication materials were collected from all Australian States and Territories and analysed using NVivo, representing a knowledge base. Data sources including semi-structured interviews with bushfire agency staff and residents in bushfire-prone localities. Interview data was analysed using thematic analysis, and emergent themes were represented using UML as a platform independent representation of the extended knowledge domain that is capable of representation in a digital space. This work unites organisational ontology, organisational epistemology and EI; the different manifestations of KM. We theorise about how organisational epistemology itself forms as part of the knowledge, where currently there is a lacking of a satisfactory end-to-end framework. The KM lifecycle, therefore, is extended by incorporating the social research processes as part of organisational epistemology to include external audiences through the themes of locality types, place and roles of individuals as volunteers and agency staff. The practical implications are that qualitative methods and toolsets can be included as part of KM to improve the development and deployment of bushfire preparedness material.
\end{abstract}

Keywords: Community Engagement, Organisational Ontology, Organisational Epistemology, Emergency Organisations, Knowledge Management

\section{INTRODUCTION}

In Australia, effective response to emergency and disaster incidents involves multiple state agencies, as well as humanitarian organisations. In this context, there is a strong tradition of volunteerism from within the community for emergencies, where people from diverse backgrounds and professions commit their time and energy to join emergency services, and then train and respond in emergencies 
situations when required. Bushfire emergency arrangements between agencies are complex and differ in individual Australian states. For instance, in Victoria there are fire services such as the Metropolitan Fire Services (MFB), whose members focus on structural incidents. In bushfire events, the bushfire fire emergency services ${ }^{1}$ are the lead agency.

Due to the regularity and ferocity of bushfires (and grassfires) in Australia, fire emergency services spend considerable resources on developing information packs to guide and facilitate residents to prepare and take actions to survive. While recognising the inputs from other services ${ }^{2}$, in the case of bushfires, information packs are developed primarily by the fire services, as lead agencies.

This paper focuses on the development of bushfire preparedness knowledge by the fire services that respond to bushfire incidents (identified in footnote 1). As the peak body for Australasian fire, land management and emergency services, the Australasian Fire and Emergency Services Council (AFAC) plays a significant role in facilitating collaboration. For example, AFAC facilitated key fire and emergency service personnel from all Australian States and Territories and this interaction resulted in the development of common descriptors and key messages for agencies and for the public, resulting in a new national catch phrase and campaign 'Prepare. Act. Survive' (National Bushfire Warnings Taskforce, 2009).

There are important lessons in how the fire services develop this preparedness knowledge as organisational learning, and in how this information is made explicit, and then received by the public. The public react in a variety of ways to the information, some residents take action to prepare. Public responses are complex and McNeill et al. (2014) examined personality traits and decision-related factors that lead to a delay in decision making. Sims and Baumann (1983) pointed to the subjective link between awareness and behaviour change (pp. 184). McGee (2005) studied social bonds within groups of people and stated that this did not significantly improve the uptake of mitigation measures (pp. 153). By contrast, Prior and Eriksen (2013) found that social cohesion expressed as 'sense of community' was important for meaningful action.

The availability of information and the variability of public responses highlights the need for a Bushfire KM-Model (KM-Model) for the development of preparedness information. The purpose of this paper is to bridge the different manifestations of KM and discuss how organisational epistemology itself forms as part of the knowledge, where the current process centric approach lacks a satisfactory end-toend framework.

\section{BACKGROUND}

The fields of qualitative research and knowledge management (KM) are often viewed as separate disciplines with different ontological roots. KM is traditionally information technology in origin, still

\footnotetext{
${ }^{1}$ Fire Emergency Agencies are the New South Wales Rural Fire Services (NSWRFS), Western Australia Fire Emergency Services Authority (FESA) of Western Australia, Victorian Country Fire Authority (CFA), Tasmania Fire Services (TFS), Australian Capital Territory Rural Fire Service (ACTRFS), Northern Territory Fire and Rescue Service (NTFAST), Rural Fire Service - Queensland (RFSQ).

2 These arrangements differ in each Australian State, but in Victoria, other support agencies are the State Emergency Service (SES), police and humanitarian organisations such as the Australian Red Cross.
} 
related to the computer-based system definition of Alavi and Leidner (2001). Information Technology (IT) based KM systems have been used since the early eighties (Kamara et al., 2002).

Avgerou (2000) noted that the computer sciences and information systems research traditionally adopted a positivist epistemology, but interpretivist approaches have gradually become more accepted. Bénel (2012) also stated that the KM notion of 'ontologies' was not declared to be related with the philosophical concept, but this term had been co-opted as 'jargon'. In view of this, the KM approach of ontology development (verifiable and conclusive) lacked reflection upon creating, testing and revising, with no place for knowledge construction and refutation (Bénel 2012).

However, in this paper, we considered favourably Bénel's belief that even systems should also provide 'digital spaces for debate between contradictory user-generated viewpoints' and allow users of our systems to have the 'hypothetical and intersubjective value of truth in mind' (Bénel 2012, p. 4). We noted that in the KM context, ontology development has been restricted by a dominant focus on process models and artefacts (Kanjanabootra et al. 2013). We adopt the position in this paper that KM may be viewed as having a symbolic-interpretivist or constructivist ontology ${ }^{3}$. In taking this view, we examine the implications of organisational epistemology for emergency agencies by bridging different manifestations of KM and discuss how the very choices of organisational epistemology, which relies on an organisation's ability to be sufficiently self-reflexive, also form part of knowledge where currently there is a lacking of a satisfactory end-to-end framework.

In the bushfire context, the knowledge boundary may be extended to incorporate the inter-subjective nature of knowledge. An approach to organisational epistemology has been proposed which shows how the concept of shared, or constructed, knowledge can be 'deconstructed' (as themes of people, locality, place, processes etc.) and applied to the development and deployment of bushfire safety publications. These themes may be subsequently enacted as part of a KM model as digital spaces for knowledge capture.

\section{METHODOLOGY}

As part of the Bushfire Cooperative Research Centre (CRC) 'Effective Communication and Communities' project, secondary data collection for the communication materials took place first in 2010 for the State of Victoria. This was recorded and catalogued, and then work commenced gathering secondary data from other Australian states and territories. One agency referred to their website as the source of all their communication material, which could be downloaded by the general public. Data on bushfire preparedness was also collected via an environmental scan which identified material from other organisations, such as the Australian Red Cross. Between July and August 2011, this environmental scan was conducted using the websites of the lead bushfire agencies. Searches of websites were also carried out to identify other sources (such as banks, newspapers, schools etc.). Some of the secondary data collected was shown as examples during the face to face interviews and related fieldwork. All primary and secondary data was coded and queried using NVivo.

To better understand how bushfire agencies communicated with the public, we conducted semistructured interviews with bushfire agency staff and residents in bushfire-prone localities (see Table 1). Key stakeholders were identified for interviews from New South Wales, Western Australia, Victoria and Tasmania. At state level, we focused on key personnel, e.g. the people at CFA or TFS Headquarters

\footnotetext{
${ }^{3}$ For a definition of symbolic interpretative interpretivism please see (Schwandt, 1994).
} 
who had community or communication engagement responsibilities. Participants were selected from a number of different locality types, namely urban-rural and holiday-maker. Participants were also selected on the basis of being at state level, local government (councils) and then residents in the different locality types. When targeting different locality types, we identified a locality as urbanrural/holiday maker. At the local council level, we identified those in charge of enforcing local regulation. The residents interviewed included holiday makers, permanent residents, volunteers etc. in each of these locality types.

We analysed the interview data, the research notes and the secondary data in combination to identify patterns/themes through thematic analysis (Braun \& Clarke 2006), an approach compatible with constructivist ontology. These themes represented meaning within the data in relation to knowledge and development of bushfire communication material. The emergent themes were then represented as UML patterns using class diagrams in order to examine and represent links between themes and to develop the KM model that was platform-independent.

\begin{tabular}{|l|l|l|l|l|l|}
\hline Participant & Australian State & M/F & Age & Education & Role \\
\hline CRCVICST04 & Victoria & F & - & Tertiary & Community Development \\
\hline CRCVICST03 & Victoria & F & - & - & $\begin{array}{l}\text { Manager, Community } \\
\text { Development }\end{array}$ \\
\hline CRCVICST08 & Victoria & M & - & - & Commander/Manager \\
\hline CRCNSWST03 & New South Wales & M & $35-44$ & Post-Graduate & Community Safety \\
\hline CRCTASST03 & Tasmania & F & $55-64$ & Tertiary & Community Development \\
\hline CRCVICANG01 & Victoria & F & $35-44$ & Post-Graduate & $\begin{array}{l}\text { Community Development } \\
\text { Coordinator }\end{array}$ \\
\hline CRCVICANG05 & Victoria & M & $55-64$ & Secondary & Schools Presenter, Volunteer, \\
& & & & Manager \\
\hline CRCWADUN05 & Western Australia & F & $55-64$ & Post-Graduate & Volunteer, Resident \\
\hline CRCWABED13 & Victoria & F & $35-44$ & Tertiary & Resident \\
\hline CRCECPKOR02 & Victoria & F & $55-64$ & Tertiary & Resident \\
\hline CRCVICANG15 & Victoria & F & $55-64$ & Tertiary & Resident \\
\hline
\end{tabular}

Table 1 - Interviewee Demographics

\section{THE KNOWLEDGE MANAGEMENT CONTEXT}

$\mathrm{KM}$, as a practice, has been developed as a strategic tool, separating information and knowledge (Hackett, 2000; Lee \& Yang, 2000; Lin, 2007; Lejeune, 2011; Schiuma, 2012). Perhaps to confuse matters with social science discourse, computer-based knowledge bases, data models or schemas are also referred to as ontologies (Farquhar et al., 1997; Holsapple and Joshi, 2003; Maedche et al., 2003; Noy and McGuinness, 2001; O'Leary, 1998).

Madhavan and Grover (1998) view knowledge creation as a social and cognitive team process and it is agreed that a number of phases such as knowledge identification, capture, storage and sharing are required (Boh, 2007, Bartholomew, 2009, Booth, 2010). Respective factors that influenced behaviours in efficiently sharing of organisational knowledge was highlighted by Nesan (2012) who identified that trust, creativity, motivation, ability, and learning influenced employees' knowledge sharing behaviour. Within this context, knowledge is highly individualised and has been described as being socially 
constructed (Berger \& Luckmann, 1991). Rubenstein-Montano et al. (2001) argued that culture, business strategies and the technological infrastructure are part of a KM framework.

Knowledge comprises experiences of people and is constructed within different contexts and with personal interpretation and reflection (Polanyi, 1962; Von Krogh et al., 2000). Meyer and Rowan (1977) and McDermott (2000) argue that knowledge is illusive and cannot be delivered solely by information technology. Knowledge is scattered, and often unstructured, with tacit knowledge existing within peoples' heads, or it may be augmented or shared via interpersonal interaction and social relationships (Nwilo \& Osanwuta, 2003; Fergus et al. 2003). Knowledge is recognised as a corporate asset and treated as with tangible assets (Davenport \& Prusak, 1998; Alavi \& Leidner, 2001; Bartholomew, 2009). Therefore, qualitative research provides the tools, methods and approaches to study and in some way capture this phenomenon (Creswell, 2007). Organisational ontology and epistemology relate to assumptions about truth and how knowledge may be accessed, captured, codified and re-used (Lejeune, 2011; Nonaka, 1994; Schwartz, 2006), thus highlighting the dependent relationships between KM and qualitative research.

Social methods are also well suited to the study of tacit knowledge in organisations as is evidenced in the works of Von Krogh et al. (1994), Nonaka (1994), Nonaka et al. (2000a), Nonaka et al. (2000b), Nonaka and Toyama (2003), Nonaka et al. (2006), Von Krogh et al. (2012), who have intrinsically linked KM to organisational epistemology.

Organisational epistemology is the study of ways of knowing in the organisation and the process of codifying and amplifying knowledge created by individuals (Nonaka, 1994; Nonaka et al., 2006). Filemon and Uriarte (2008) included people's skills, competencies, ideas, intuitions, commitments and motivations. These attributes of people in organisations can be captured somewhat through interviews which facilitate access to the 'knowing' - tacit knowledge within organisations.

There are implications on how knowledge is organised and the value of knowledge taxonomies (Alavi \& Leidnerm, 2001). Holsapple and Singh (2012) underpinned the knowledge structure for electronic commerce with a definitional taxonomy including descriptive, procedural and reasoning knowledge. Kakabadse et al. (2003) also discuss the incorporation of business processes, information technologies, knowledge repositories and individual behaviours.

\section{ORGANISATIONAL KNOWLEDGE DOMAIN}

Similar to the product design workflows of Catalano et al. (2008), the consideration of KM can be essential to how bushfire safety material is developed. Where the current process centric approach lacks a satisfactory end-to-end framework, this paper will now bridge the different manifestations of KM and discuss how organisational epistemology itself forms as part of the knowledge. Providing the 'digital space' for the inclusion of the public audience as part of organisational epistemology are key aspects of this work.

Two ideological fields exist, where organisational epistemology and ontology remain within knowledge philosophy and enterprise integration (EI) within the commercial domain. While organisational ontology remains in research, it is not well supported either by toolsets as enterprise integration. The development of toolsets such as NVivo (QSR International, 2013) and Protégé (Stanford University, 2009) may also be an indication of how the two fields remain separate, where NVivo caters to the qualitative research community and Protégé for development of Web Ontology Language (OWL) compliant ontologies. If organisational ontology and organisational epistemology are considered to be integral concepts to KM, then existing integration systems that only consider ontology as an end-result (excluding the intersubjective nature of knowledge creation) may yet fall short in support of the knowledge lifecycle. 
The interviewing process is one of the many methods used in social research (Kvale \& Brinkmann, 2009; Ambrosini \& Bowman, 2001; Desouza, 2003; Frey and Fontana, 1991; Layder, 1998) and may be applied in support of organisational epistemology. NVivo allows researchers make sense out of "raw" semi-structured data, providing memo links, coding stripes and models, and arguably, its use in research is a form of KM. Constructs of NVivo such as Source, Nodes etc. are also different to the ontology of Classes, Instances and Objects, which underpins the syntax of the Web Ontology Language (OWL).

We propose a unifying framework for organisational knowledge which has been developed based on the research literature (Figure 1). The conceptual framework proposed comprises three components. There is an overarching component of organisational ontology and two other components of organisational epistemology and enterprise integration (EI), where the latter refers to the involvement of the technology platforms that fulfil the role and functions of information integration as used by Chen et al. (2008).

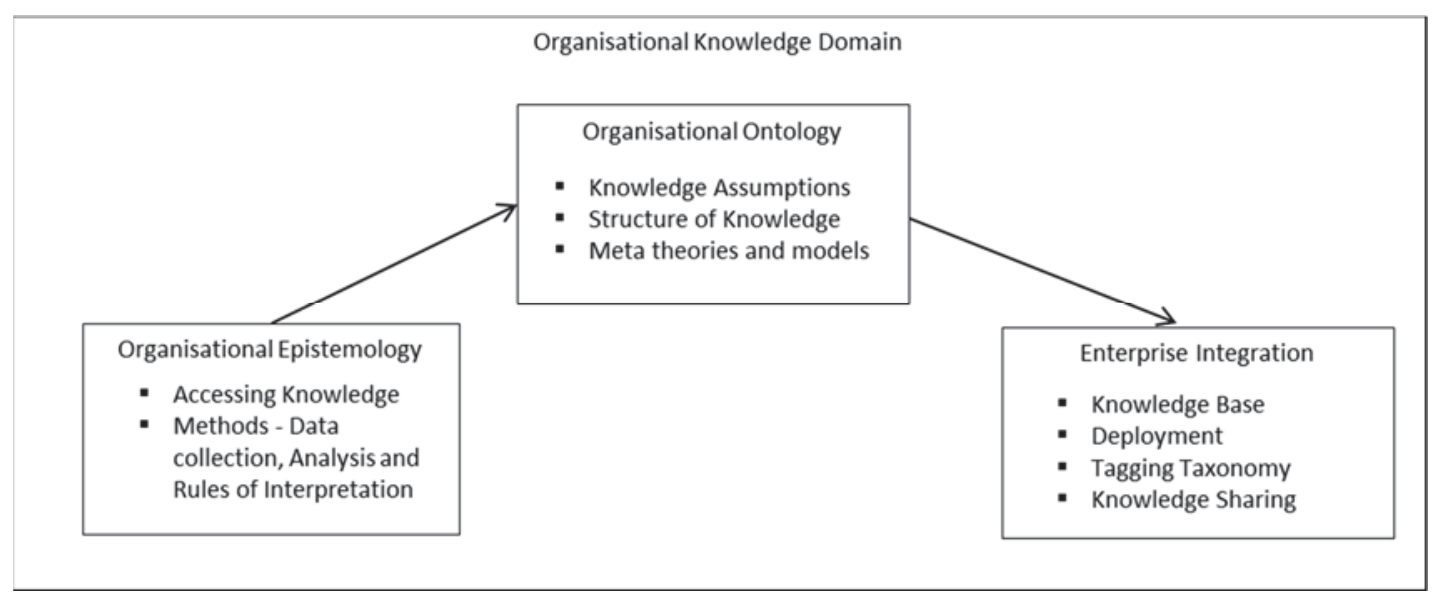

Figure 1. A unifying framework for organisational knowledge

EI relates to technology and knowledge meta-theories relate to the meta-theory that underpin our assumptions about knowledge. This distinction may also be seen in the works of (Davenport et al., 1998) and (Saito et al., 2007). With EI, 'ontology' tends to be based upon enterprise functionality, in the form of service or process models and (event based) execution (Bussler, 1996; Scheer \& Nüttgens, 2000; Chandrasekaran et al. 1999). Therefore, this model of unifying framework (Figure 1) affords a conceptualisation of the proposed KM architecture.

\section{Organisational Ontology and Epistemology}

An ontological position determines data collection and analysis and interpretation. In taking an interpretive view, knowledge is seen as socially constructed and this ontological position determines how data is collected and interpreted, such as through interviews, observations and document analysis. The way we use qualitative research interviews, seeks to describe meanings of central themes in the lives people and to understand how meaning is determined (Kvale, 2006; Britten, 1995; Opdenakker, 2006; Kvale \& Brinkmann, 2009). Accepting Fisher's concept of knowledge as a form of social capital (Fisher, 2013), we argue that representing organisational knowledge as solely functional models leads to a highly constrained view, which does not provide the inter-subjective space as discussed by Bénel (2012). It is highly constrained because there exists richer, complex and sometimes subjective content to be accessed through qualitative methods. 
In interviews, audio recordings provide a representation of what was said, but much of the conversation in terms of highly valuable contextual and personal information is often not captured, or forgotten in fields notes that many researchers are unsure what to do with (Layder, 1998, pp. 59). After recording and transcribing the interviews, it is necessary for the interviewer to capture observations such as the environment, or attitude/persona of the interviewee (Memon \& Higham, 1999) and possibly even mannerisms communicated through body language and sounds such as laughter or long pauses in response (Creswell, 2007). Summaries and additional contextual information captured brings a new dimension to the data, and the analyst one step closer to the data than is possible with a typed verbatim transcript alone (Silverman, 2006).

Enterprise Integration (EI) technologies assist in the process of data collection, storage, analysis and publication. Examples of integration platforms are IBM's WebSphere MQ and other Web-service based solutions to integrate multiple software applications so that they work together and exchange information (Bieberstein et al., 2005). EI applications that focus on explicit and structured functional knowledge, such as document management or enterprise resources management, often do not focus on tacit knowledge or context. Therefore we propose that EI ontologies are narrowly focused on a functional approach.

\section{The Functional Approach of Enterprise Integration (EI) Ontologies}

Organisational ontology is both complex and extensive, and ontologies developed in the fields of enterprise modelling tend to view business operations from a perspective of functionality and information integration (Davenport \& Short, 2003). Business functionality has also been described in terms of contracted services between an organisation and its employees or customers (Weske, 2012; Wegmann et al., 2008).

EI results in a focus on business where ontology comprises processes and information schemas and EI epistemology is based on using modelling languages that record as many facts as possible from data models, function trees and organisation views. Therefore, process and information models form the constructs of many enterprise modelling architectures (Vernadat, 2002). The CIMOSA ${ }^{4}$ ontology captures enterprise operations using Function, Information, Resource and Organisation viewpoints (AMICE, 1991). The TOVE (Toronto Virtual Enterprise) Ontology (Fox et al, 1996; Grüninger et al., 2000) is based around defining semantics to enable data sharing. The Architecture of Integrated Information Systems (ARIS) ontology comprises function, organisation and resources (Scheer \& Nüttgens, 2000). We build on these ontologies and reference models to develop a conceptual architecture of the organisational knowledge domain.

\section{Developing the Organisational Knowledge Domain}

People draw on knowledge to make sense of situations, to communicate, and to act. Organisational knowledge is complex (O’Dell \& Grayson, 1998; Ardichvili et al., 2003) and we have argued so far that organisational ontology is far more extensive than just knowledge that is distilled as process and business process models. Developing the Organisational Knowledge Domain (see Figure 1) and mapping of toolsets demonstrates how the existing KM framework may be extended.

The notion of organisational knowledge creation locates knowledge where humans interact, which can be considered as a cyclic process (Blackler, 1995; Nonaka, 1994; Demarest, 1997; Alvesson \&

\footnotetext{
${ }^{4}$ Computer Integrated Manufacturing - Open System Architecture
} 
Kärreman, 2001). This occurs at different levels of the organisation (Inkpen \& Dinur, 1998). Fisher (2013) discussed the concept of social capital as several levels through which knowledge is acquired and transmitted between individuals and government organisations. In the bushfire context, organisational epistemology involves networks and interactions of people and this view of the knowledge domain is shown using the UML use-case notation (Figure 2). Creative processes in agencies lead to the production of the preparedness information and knowledge is generated through interactions with the public when materials are handed out. Key to the knowledge domain is the 'includes' relationship which elements such as 'Public' is represented by an aggregation of agency staff, volunteers, statutory officers and even researchers.

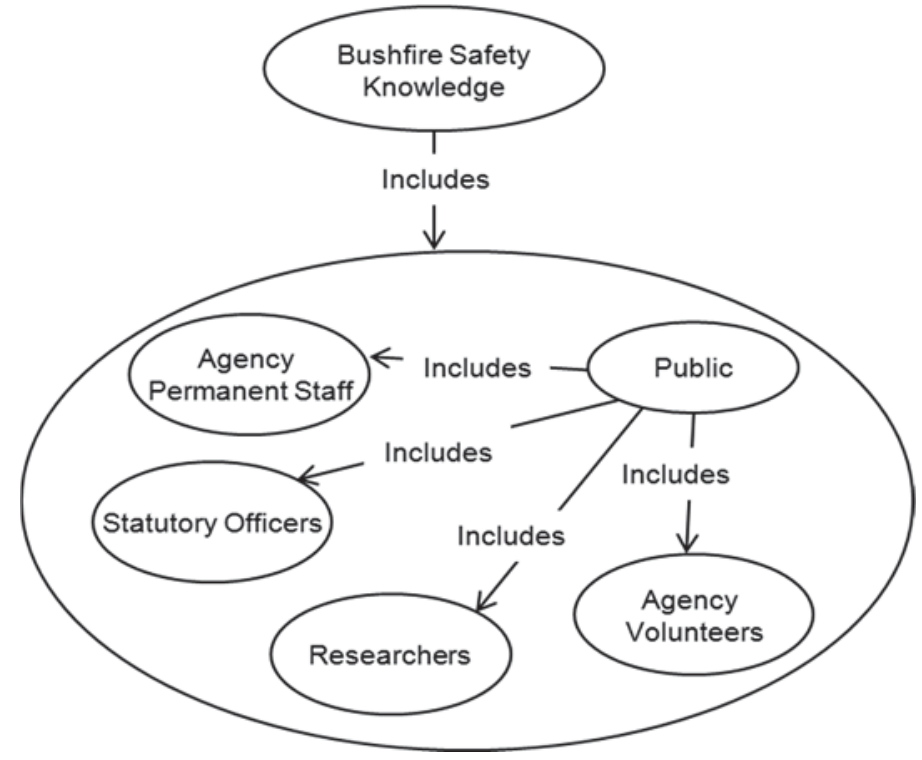

Figure 2. Mapping of individuals involved in the knowledge lifecycle

A 'visualisation' of organisational knowledge has offered a step beyond process centric (or reductionist) abstractions and organisational KM needs go beyond codifying knowledge as workflows and as technical platforms. Qualitative research practices should be drawn upon, as organisational epistemology, to 'unpack' the meanings of themes. Thematic analysis guides how concepts may be interpreted and handled; this is discussed extensively by Braun and Clarke (2006), and Ryan and Bernard (2003).

The two domains of KM may also be illustrated through examples of their different toolsets adopted. In EI, organisational ontology may be defined in the Unified Modelling Language (Rumbaughet al. 1999) or in the Object Web Language (OWL) through applications such as Protégé. In social research, NVivo is a software application that supports the processes of qualitative raw data handling (interview texts, audios etc.), coding and thematic analysis. Although NVivo does not produce an ontology that is OWL compliant, it features greater recognition of organisational epistemology through its support of social research. Therefore we argue that socially-oriented processes that lead to the construction and interpretation and emergence of knowledge themes are not well served by contemporary EI 'ontology' solutions alone. The proposed organisational knowledge domain (Figure 3) provides a place for qualitative approaches to capture richer, complex and sometimes subjective content in KM practice. 


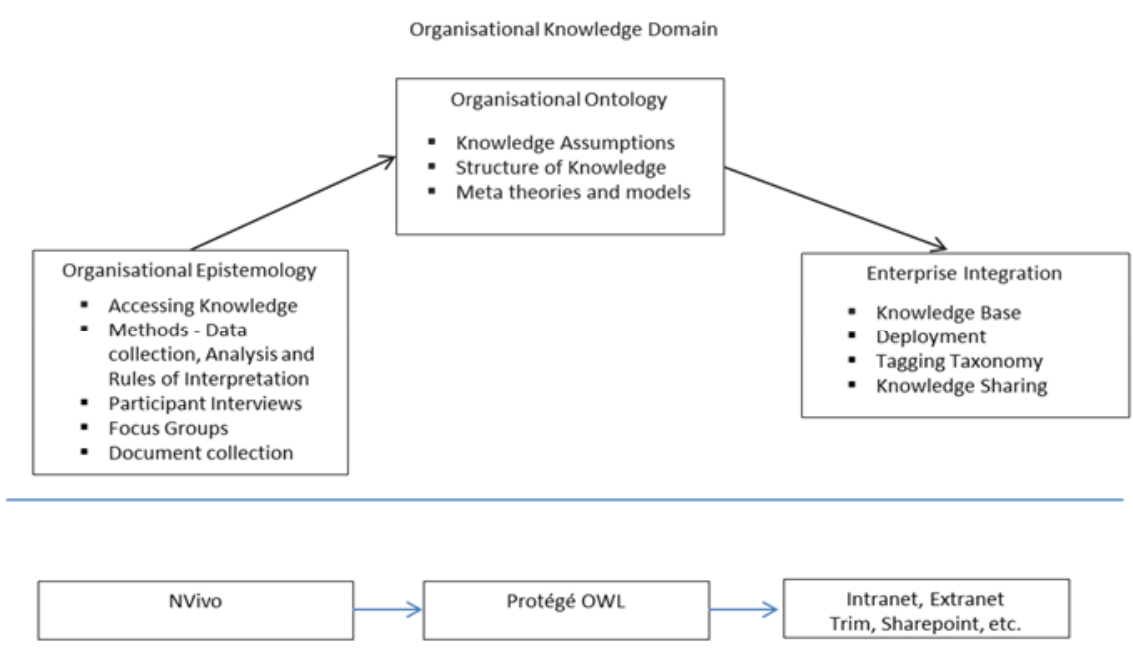

Figure 3. Providing for richer, complex and sometimes subjective content in KM practice

\section{Australian Bushfire Communications: A Case Study}

In Australia, the State Emergency Service (SES) provides preparation and urgent community assistance for storms and floods. For bushfires, public preparedness is underpinned by how the fire services, as lead agencies, develop information packs and facilitate residents to take action. As alluded to earlier, it has been reported that the public generally ignores the abundant amount of preparedness information available (Rhodes et al., 2011; Australia Parliament, 1984, pp. 27) and there are lessons to be learnt from how safety publications are designed and disseminated.

Ordoñez and Serrat (2009) argue that widespread dissemination is 'a core responsibility of any organization tasked with generating and sharing knowledge products, especially of new kinds of unique (and uniquely valuable) content that are as usable and accessible as possible'. The need to produce and disseminate quality information is also recognised along with cultivating community knowledge and public engagement (O'Dubhchair et al., 2001). McDermott (2000 pp. 28) argued that 'we need to focus on the community that owns it [knowledge] and the people who use it, not the knowledge itself'. O'Dubhchair et al., (2001) argued that communities must develop capacities for learning by interfacing with local and regional agencies.

This need to improve design and dissemination may be viewed as a KM problem. Whereas the main body of literature on internal KM tends to focus on organisational knowledge (Nonaka et al., 2006; Dalkir, 2013), this work examines how external audiences, whom McDermott (2000) described as users of the knowledge, may be included as part of organisational epistemology, in the development of preparedness material.

The view of organisational knowledge proposed in Figure 4 posits the shared conceptual models in the form of enterprise ontologies. This was developed with the ideas of Maedche et al. (2003) in mind, emphasising the importance of integrating knowledge across databases, file systems, as well as providing the capacity to capture tacit knowledge held by individuals. Therefore, the KM architecture distinguishes both process models (as EI ontology) and knowledge models which extends towards tacit content, in our attempt to provide the digital spaces for the "hypothetical and inter-subjective value of truth in mind' which Bénel $(2012$, p. 4) called for. In Figure 4, subjective knowledge is denoted as 'Knowledge Models', which is differentiated from 'Process Models'. 
A digitised collection of bushfire preparedness material, along with interview data, was organised and analysed in NVivo. The role of NVivo is located as the 'Knowledge Information' component of the KM architecture, shown previously (Figure 3), and the meta-model is captured in UML classes, documenting the knowledge structures that are relevant to the development of bushfire preparedness material. NVivo supported in-depth data analysis, by providing the ability to code images, audio and video sources, thereby reflecting complicated knowledge than solely plain text.

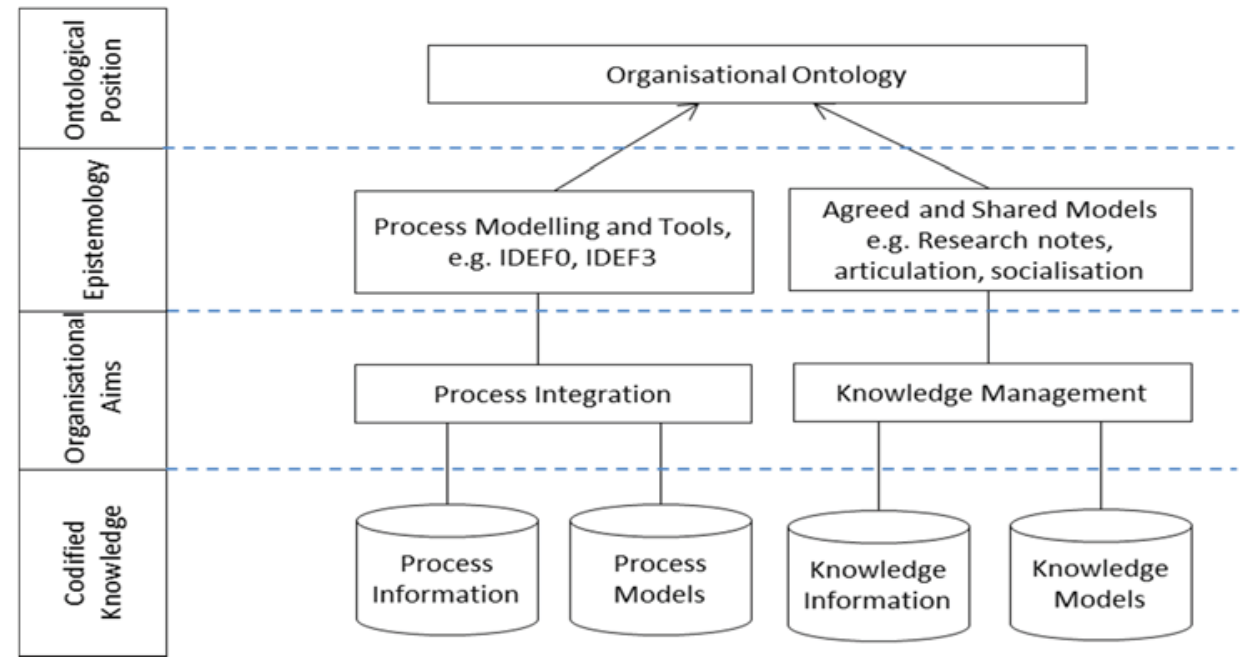

Figure 4. Positioning knowledge models in KM architecture

The KM architecture (Figure 4) was initially developed out of underlying issues of document and version control. Organisational boundaries later were identified when bushfire preparedness material was collected and the roles and activities of those responsible for knowledge in emergency organisations were explored. NVivo supported this process through its ability to manage a range of data including interviews and communication materials, as well as coding of bushfire safety themes as they emerged. The schema of the KM-Model (Figure 5) gives an overview of the themes including people, roles, processes, locality, place and dissemination experiences. The schema now goes beyond the reductionism of process modelling. Although functional representations as 'Processes' are a component of knowledge, there are other concepts that develop further insights into knowledge, such as with individuals and their roles, the significance of locality and its link to risk, the meaning of place, the development and dissemination of key messages and originating agencies. Figure 5 provides an overview of the themes and also indicates that these themes are related in particular ways as shown later using the UML class notation. 


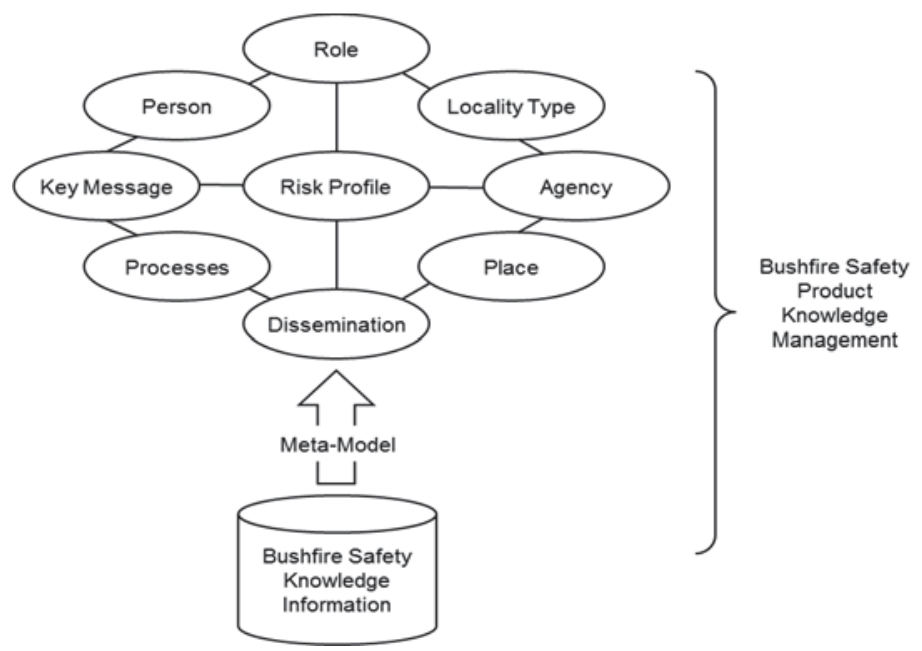

Figure 5. The Bushfire KM-Model

In a more formal format, the schema of the Bushfire KM-Model is presented using UML class diagram which enables integration between 'hard' EI functional concepts and 'soft' intersubjective themes.

\section{SCHEMA OF THE BUSHFIRE PREPAREDNESS KNOWLEDGE MODEL}

The schema of the KM-Model is a layout of themes that were identified from the analysis of the communication material and interviews conducted. The model was also developed to accommodate processes and knowledge of bushfire agencies, as well as the knowledge contributed by residents, the combination of which captures aspects of community knowledge. Themes, such as products, processes, roles and persons offer elements against which knowledge may be embedded. The following sections describe how UML classes are used as the 'containers' for instances of tacit knowledge.

\section{Capturing Tacit Knowledge}

Knowledge is represented in bushfire education material and is also inherent in social processes and interactions. There are examples where knowledge is exchanged or constructed through informal interactions between agency personnel, or formally facilitated through AFAC.

There is a tradition of volunteering in Australia and fire emergency agencies also comprise volunteer personnel who provide the vital capability to deal with emergencies. The boundary of knowledge is 'elastic' and external knowledge is implicitly involved because agencies comprise employed staff and volunteers. Knowledge is exchanged as agencies distribute the material and it is inclusive of wider segments of the community.

Davenport and Prusak (1998) and McDermott (2000) argued that knowledge is embedded not only in documents or repositories, but in organisational routines, processes, practices and organisational norms. An example of how organisational knowledge may be codified as business processes may be found in (Johannsen \& Fill, 2014). Building upon the work of O'Dubhchair, Scott and Johnson (2001), the KMModel focuses on a different context, on community. This focus on community is achieved through the themes of agency, service, roles, person, process, products, place and locality. Importantly, the KMModel provided a means for managing the accumulated knowledge, to provide a tool for easier accounting for an agency's knowledge assets and to support ways through which agencies may better target different segments of people. The focus was on how concepts of processes and people intersect as knowledge products are developed and distributed. 
The KM-Model (Figure 6) was developed in UML to reflect themes that emerged from analysis of key agency personnel and residents in different localities. Knowledge is the combination of agency processes and knowledge contributed by residents - which capture aspects of 'community memory'. Elements in the KM-Model underpin knowledge associated with products, processes, roles and persons.

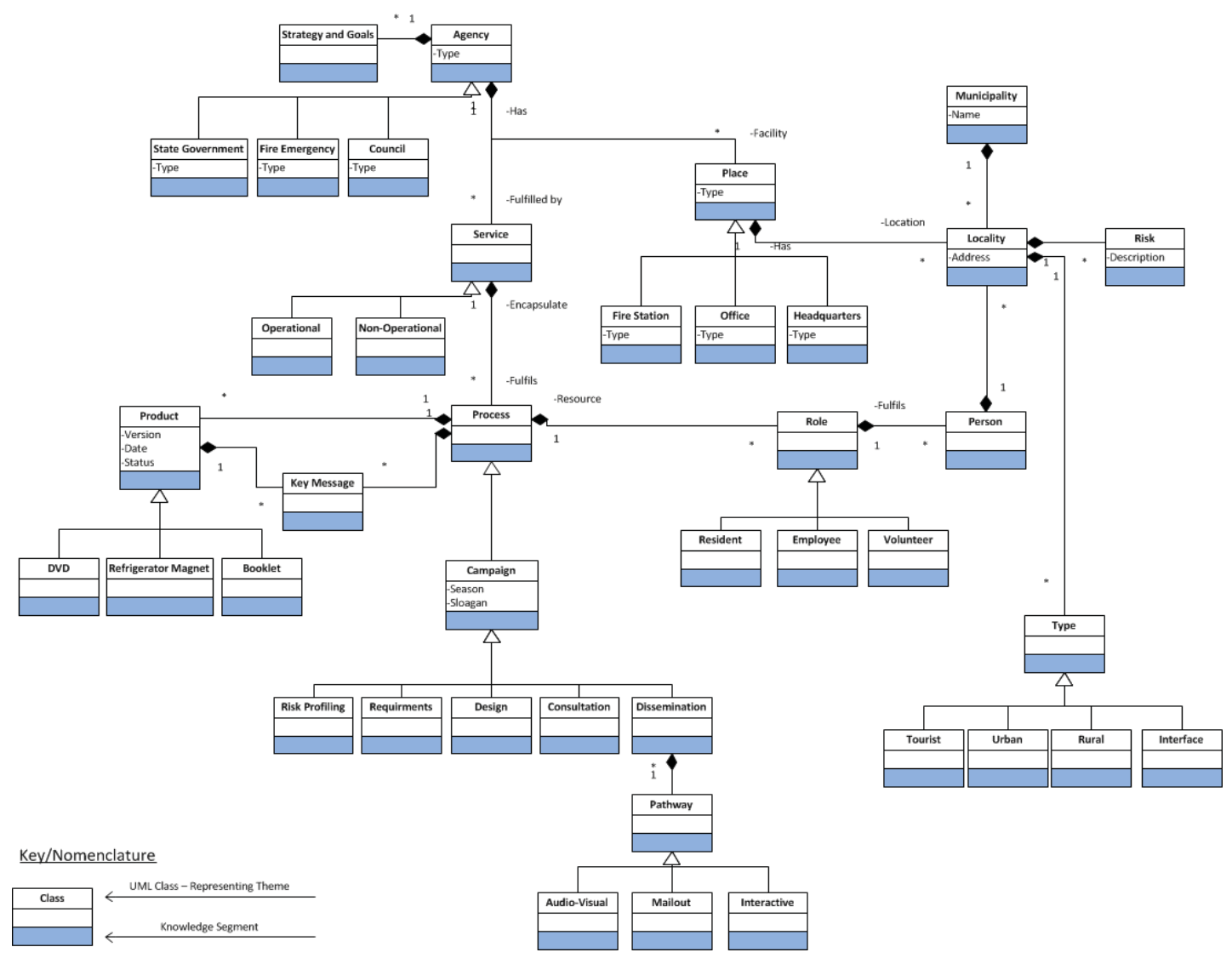

Figure 6. The UML Schema of the Bushfire-KM Model

\section{Originating Agency}

The Originating Agency identified the source of the knowledge product. There is a 'Lead Agency' which depends on the nature of the emergency, but the actual situation is much more involved. 'Lead agencies' in the context of bushfire/grassfire emergencies were the CFA, RFS, FESA, ACT RFS, etc. Other agencies were the Office of the Premier of Victoria, Department of Health, Fire Services Commissioner, individual Councils. Therefore, the element 'Originating Agency' identifies the particular agency associated with a particular knowledge product. 


\section{Agency}

'We have multiple agencies wanting to engage communities about fire at different times.... So we've been working with Red Cross this year to make sure that all fire planning's consistent... not selling two different kinds of planning approaches.'

CRCVICST04

\section{Services}

'Services' are often described through agency websites as 'What we do'. As an example, one agency provided wildfire suppression, structural fire suppression, and providing community awareness and education. These services may be formally listed as a catalogue that encapsulates service level agreements. The class 'Service' caters to the themes of organisational changes or reconfiguration to focus on public engagement.

\section{Service}

'[Brigades] have seen some progress within their community and they are more willing to take and wanting to be resourced and trained to be able to do this [community education] within their communities. Whereas when I first met with them, they kind of were, no we're just operational, we don't do that sort of stuff.'

CRCTASSTATE03

'.....A lot of the fire officers, they join thinking their job is to go out and put wet stuff on the red stuff, it's not. They spend 5 or 10 per cent of their time doing that. The other 95 per cent of their time, they've got to be out there in the community. To be talking up to prevent fires...'

CRCVICST08

\section{Organisational Processes}

Organisational processes may be classified as operational, tactical and strategic processes and correspond with local, regional and state levels, where local operational processes are executed for example, by individual brigades. Process knowledge is captured at a strategic level where one interviewee described the need to effectively manage the development of messages. There were also examples of informal collaboration processes, but knowledge sharing between agencies is facilitated by AFAC in the development of key messages. Sub-processes were often identified such as consultation, public engagement, interactive forums and other forms of dissemination such as mass mail-outs.

\section{Process \\ ‘......we like to joint badge our media releases for sure, and particularly our media campaigns and our launches. Anytime we do a media launch we involve the minister and get that... everything's all in synergy that way....it's almost a case of let's go to a neutral corner....' \\ CRCVICST08}

The theme 'Campaign' emerged where some interviewees related 'Campaign' to a number of concepts, including development of key messages, public consultation and dissemination. 'Campaign' was an abstract theme, such how interviewees described television and radio campaigns. As an overarching 
element it contained attributes, such as campaign slogan. Examples of Campaign slogans were 'Fire Ready' or 'Prepare- Act-Survive'.

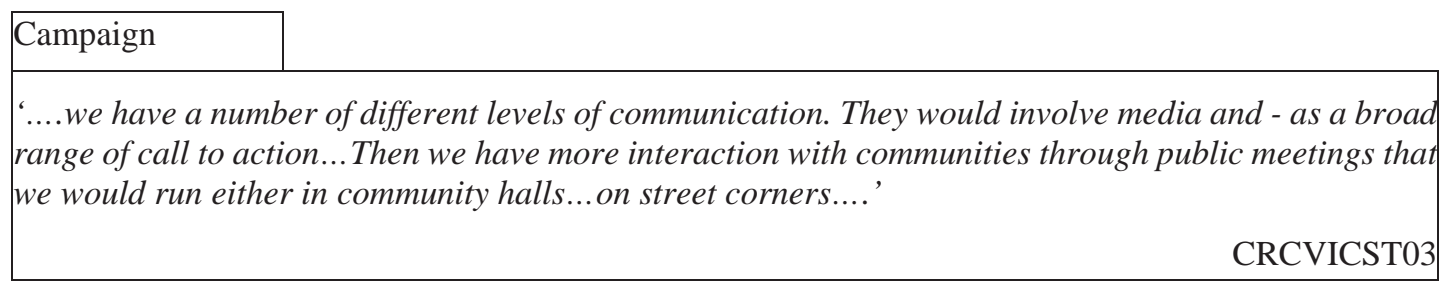

\section{People and Roles}

Analysis of the fire emergency domain identified key personnel (modelled as Persons) as those who have tacit knowledge. Tacit knowledge can be captured through interviews with the key or domain experts and conceptually this was linked through Roles. This theme captured individual roles, where interviewees may reveal they also have roles as volunteer fire-fighters, separate to their occupation.

Agency members act in different Role(s), where some are subject matter experts, responsible for production and of the preparedness information, who also act as volunteers in their own local brigades. Often, volunteer personnel performed communication roles external to the organisational boundaries through on personal networks. The public or residents also play a role during the processes of public consultation.

The need for a qualitative interviewer to capture observations such as the environment, or attitude/persona of the interviewee and mannerisms was identified earlier (e.g. Memon \& Higham, 1999; Creswell, 2007). In relation to roles and environment, an interview was arranged with a local councillor, also a police officer. The researcher noted that the location was conducted at a police station (classified as Place of work) and research field notes reflected the interviewee's stilted and guarded responses that seemed to stem from the role of a police officer. Such research notes are used in analysis and may inform readers of the researcher's observations. The following illustrates another example of how roles may be described.

\begin{tabular}{l}
\hline Person, Role \\
\hline 'I'm a mum, granny, teacher and also a member of the local fire brigade and a number of environmental \\
groups ....In addition to being a regular volunteer bushfire firefighter, I'm what's called a facilitator of \\
an organisation called Bushfire Ready....I'm also caring for my elderly, retired, farmer uncle in my \\
house...At home, I do - I guess the best description is technical writing.' \\
CRCWADUN05 \\
\hline
\end{tabular}

\section{Place and Locality}

There was significance in the way in which interviewees spoke of place and locality. Some interviewees spoke of places as a distinct concept to locality, for example, referring to a fire station, or to a meeting place, a place of work or a place of worship. The distinction between place and locality is also found in the work of Day and Murdoch (1993). The fire station may be mentioned as the only focus place for a small locality, or absence of a local shopping facility. The abstract class 'Place' caters to this concept and other specific instance of sub-classes can be created, such as 'Station', 'Headquarters', or 'Council Office'. 
Place

'There's not a shopping centre as such. So there's not this bringing together of the population where you're going to buy your litre of milk and you see someone else getting their morning paper and you say g'day and this sort of stuff'.

CRCWABED13

Closely linked to the concept of Place, was Locality, which related to spatial boundary such as a town or a suburb. In relation to this study, some interviewees described characteristics of living in a holiday maker locality. Knowledge associated with this class may be related to Peri-urban, Sea change, and Rural localities. The targeted strategies are developed for at-risk localities and knowledge segments give insight into barriers against acceptance and implementation of strategies that may have an impact upon local brigades.

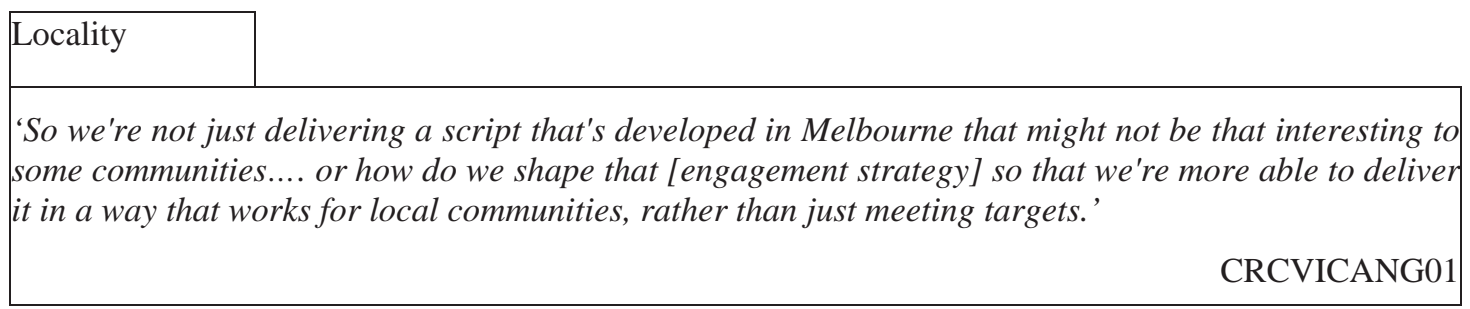

\section{Risk Profile}

Associated with locality, is the component of Risk, which is related to the locality's risk profile. An example of how this knowledge may impact the relevance of bushfire communication was illustrated by one interviewee who said that residents largely ignored communication because of the perceived risk profile of the locality and a lack of consensus on terms used in communication.

Risk Profile

'I think that terminology bushfire awareness, too, is a bit of a misnomer for people. They just don't think that actually them, because we're all grassfire area, and slightly residential, as well. They'd be more concerned of... a factory explosion fire.... So, they're - don't think bushfire, that name bushfire, they'll think, oh that's not us.'

CRCECPKOR02

\section{Dissemination}

The value of the knowledge relies heavily on its effective dissemination to the target audience. The Dissemination class denotes the processes of delivery, whether this involves the engagement of individuals or through television or radio campaigns. An effective dissemination strategy will continue to evolve and the segments of knowledge relating to the utilisation of the product can include reasons why particular pathways fail. 
Dissemination, Pathway

'... they've bombarded people with too much...these kits that they sent out to every house and admittedly some houses got four to five. Every person that was an adult in that house got one. But there were four or five different books..... and people were scratching their heads.........'

CRCVICANG05

'I think just from handing this out and speaking with people, this is a document that needs to be explained....rather than just hand it to them.....you try to explain the different things that could happen..... Some will change their mind by the end of the conversation.'

CRCNSWST03

'if you stand there with a handful of brochures, some balloons on a string and while people are walking past, you say, would you like a balloon, hello little child, whatever, they stop, they talk and before you know it, you're having really meaningful conversations. We could engage in 200 in-depth conversations in a day and come home exhausted, or you can sit back on your chair and wait for people to come to you and have 20 conversations'

CRCVICANG 15

\section{DISCUSSION}

The use of 'ontology' is contested from the perspectives of two different disciplines. Bénel (2012) stated that ontology had been adopted 'jargon' in the computer sciences, and we also noted this use in contemporary EI and KM applications. With this point in mind, we approached KM from two perspectives; firstly we critically examined KM theory and secondly the implications of organisational epistemology as a philosophy on extending the KM lifecycle and framework.

The review of literature showed that contemporary EI and KM practice has been restricted by an epistemology that focuses on process models and process integration which can be reductionist. An approach to organisational epistemology has been proposed which accepts that knowledge can be intersubjective. This paper has presented a knowledge domain which develops 'soft' KM as separate to 'hard' process integration (EI) and sought to develop the 'digital spaces' which Bénel (2012, p. 4) alluded to.

The extension of the KM cycle to include qualitative approaches was illustrated by the mapping of a qualitative toolset such as NVivo, within the knowledge management domain. This mapping differentiated 'Knowledge Models' from 'Process Models', but showed how an organisation's ability to be self-reflexive (e.g. triple-loop learning) may also be captured and integrated as part of the KM lifecycle.

The concept of knowledge models was applied to the case of bushfire safety materials for Australian bushfires, where we develop a KM-Model was developed to address how themes of community knowledge can be applied to the development and deployment of bushfire safety publications. We found the factors influencing the public's reaction to bushfire preparedness are complex, but we were influenced by Ordoñez and Serrat (2009), Carlsson (2004) and Alavi and Leidner (2001) who stated that capacities for learning and action depends on people being genuinely interested in participating in a continuous learning and knowledge sharing process. Knowledge around such capacities for learning will not be captured using process-centric EI approaches. The need to capture external sources was also alluded to by Quintas et al. (1997), who argued that part of the aim was 'supporting the acquisition of 
knowledge from external sources, and developing the capability to assimilate and utilize that knowledge; to ensure that new knowledge is distributed to those who require it'.

The KM-Model developed in this paper attempts to extended the boundary of knowledge wider to encapsulate public audiences through the themes of locality, place and different locality types. The focus was widened beyond organisational processes that produce the knowledge material and includes the view of the agency personnel as they use the preparedness material in their public engagement. The KM-Model also caters to capturing how recipients perceive the mode of delivery at the agency-public interface.

Qualitative research provided methods for data collection, analysis and presentation of information provided the means to extend the reductionist process-centric view of EI ontology to include subjective interpretations of bushfire themes. To define this 'digital space', the themes of people, locality, place, processes, or dissemination strategies were represented in UML. The KM-model bridges themes and provides a step towards further translation into other KM formalisms such as OWL.

\section{FURTHER WORK}

Further work should be carried out to extend the KM approach across multiple agencies and multiple hazards and agencies in Australia and even internationally, to include flood, storms, tropical cyclones and pandemics. Oliveira et al. (2002) discussed the evolutionary process of KM as initially document management systems. Maturity models define a number of dimensions or process areas at several discrete stages or levels of maturity, with a description of performance at various levels of granularity (Ahern et al., 2003, Paulk et al., 1993). The idea of an organisational 'maturity model' for KM has been presented for a number of industries including construction (Robinson et al., 2006). Further work should develop the concepts of organisational capability maturity and potentially adopt KM capability frameworks for application to bushfire emergency organisations

\section{ACKNOWLEDGEMENTS}

The authors gratefully acknowledge the funding of the Bushfire CRC. We are also grateful to the various bushfire agencies, particularly to Damien Killalea of the Tasmanian Fire Services and John Schauble of the Office of the Fire Services Commissioner, Victoria, who facilitated access to bushfire preparedness material. We would also like to acknowledge the work and conversations with researchers of the Centre of Sustainable Organisations and Work (CSOW) and School of Business IT and Logistics of RMIT, and across other universities who all contribute to this valuable cross-disciplinary nature of research.

\section{REFERENCES}

Alavi, M. and Leidner, D.E. (2001), "Review: KM and KM systems: Conceptual foundations and research issues”, MIS Quarterly, pp. 107-136.

Alvesson, M. and Kärreman, D. (2001), "Odd couple: making sense of the curious concept of KM", Journal of Management Studies, Vol. 38 No. 7, pp. 995-1018.

Ambrosini, V. and Bowman, C. (2001), "Tacit knowledge: Some suggestions for operationalization". Journal of Management Studies, Vol. 38 No. 6, pp. 811-829.

AMICE, (1991), CIMOSA: Open System Architecture for CIM, 2nd revised and extended edition, Springer, London.

Ardichvili, A., Page, V. and Wentling, T. (2003), "Motivation and barriers to participation in virtual knowledge-sharing communities of practice", Journal of KM, Vol. 7 No. 1, pp. 64-77. 
Australia Parliament, House of Representatives, Standing Committee on Environment and Conservation and Milton, P. (1984), Bushfires and the Australian Environment, Australian Government Publishing Service, Canberra.

Avgerou, C. (2000), "Information systems: what sort of science is it?", OMEGA - The International Journal of Management Science, Vol. 28, No. 5, pp. 567-579.

Bartholomew, D. (2009), Building on knowledge: developing expertise, creativity and intellectual capital in the construction professions, Wiley-Blackwell.

Bénel, A. (2012), Where do 'ontologies' come from? Seeking for the missing link, in 3rd International Symposium on the Web and Philosophy (PhiloWeb), April 17th, 2012, Lyon.

Berger, P.L. and Luckmann, T. (1991), The social construction of reality: A treatise in the sociology of knowledge, Penguin, London.

Bieberstein, N., Bose, S., Walker, L., and Lynch, A. (2005), "Impact of service-oriented architecture on enterprise systems, organizational structures, and individuals", IBM Systems Journal, Vol. 44 No. 4, pp. 691-708.

Blackler, F. (1995), "Knowledge work and organizations: an overview and interpretation", Organization Studies, Vol. 16 No. 6, pp. 1021-1046.

Boh, W.F. (2007), "Mechanisms for sharing knowledge in project-based organizations", Information and Organization, Vol. 17 No. 1, pp. 27-58.

Booth, C. (2010), "KM for Electric Power Utility Companies", in Metaxiotis K. (Ed.), Intelligent Information Systems and KM for Energy: Applications for Decision Support, Usage, and Environmental Protection, IGI Global, New York.

Braun, V. and Clarke, V. (2006), "Using thematic analysis in psychology", Qualitative Research in Psychology, Vol. 3 No. 2, pp. 77-101.

Britten, N. (1995), “Qualitative interviews in medical research”, British Medical Journal, Vol. 311 No. 6999, pp. 251-253.

Bussler, C. (1996), "Specifying enterprise processes with workflow modelling languages", Concurrent Engineering, Vol. 4 No. 3, pp. 261-278.

Carlsson, S.A., (2004), "Enhancing Product Development Through ICT Based Relationships with Customers and Consumers", in Proceedings of the European Conference on Information Systems (ECIS), Paper 45.

Catalano, C.E., Camossi, E., Ferrandes, R., Cheutet, V. and Sevilmis, N., (2008), "A product design ontology for enhancing shape processing in design workflows", Journal of Intelligent Manufacturing, Vol. 20 No. 5, pp. 553-67.

Chandrasekaran, B., Josephson, J.R. and Benjamins, V.R. (1999), "What are ontologies, and why do we need them?", Intelligent Systems and Their Applications, IEEE, Vol. 14 No. 1, pp. 20-26.

Chen, D., Doumeingts, G. and Vernadat, F. (2008), “Architectures for enterprise integration and interoperability: Past, present and future”, Computers in Industry, Vol. 59 No. 7, pp. 647-659.

Cook, S.D., and Brown, J.S. (1999), "Bridging epistemologies: The generative dance between organizational knowledge and organizational knowing”, Organization science, Vol. 10 No. 4, pp. 381-400.

Creswell, J.W. (2007), Qualitative inquiry and research design: Choosing among five approaches, SAGE Publications, Thousand Oaks CA.

Dalkir, K. (2013), KM in theory and practice, Routledge, Chicago.

Day, G. and Murdoch, J. (1993), "Locality and community: coming to terms with place", The Sociological Review, Vol. 41 No. 1, pp. 82-111. 
Davenport, T. and Prusak, L. (1998), Working knowledge: how organizations manage what they know, Harvard Business School Press, Boston.

Davenport, T.H. and Short, J.E. (1990), “The New Industrial Engineering: Information technology and business process redesign”, Sloan Management Review, Vol. 31 No. 4, pp. 1-31.

Davenport, T.H., David, W. and Beers, M.C. (1998), "Successful KM projects", Sloan Management Review, Vol. 39 No. 2, pp. 43-57.

Demarest, M. (1997), “Understanding KM”, Long Range Planning, Vol. 30 No. 3, pp. 374-384.

Desouza, K.C. (2003), "Facilitating tacit knowledge exchange", Communications of the ACM, Vol. 46 No. 6, pp. 85-88.

Farquhar, A., Fikes, R. and Rice, J. (1997), “The ontolingua server: A tool for collaborative ontology construction", International Journal of Human-Computer Studies, Vol. 46 No. 6, pp. 707-727.

Fergus, P., Mingkhwan, A., Merabti, M. and Hanneghan, M. (2003), "Capturing Tacit Knowledge in P2P Networks", in 4th EPSRC Annual Postgraduate Symposium on the Convergence of Telecommunications, Networking and Broadcasting (PGNet2003), Liverpool, UK.

Filemon A. and Uriarte J., (2008), Introduction to KM, ASEAN Foundation, Jakarta, Indonesia.

Fisher, R. (2013), “A Gentleman's Handshake: The Role of Social Capital and Trust in Transforming Information into Usable Knowledge”, Journal of Rural Studies, Vol. 31, pp. 13-22.

Fox, M.S., Barbuceanu, M., and Gruninger, M. (1996), “An organisation ontology for enterprise modeling: preliminary concepts for linking structure and behaviour", Computers in Industry, Vol. 29 No. 1, pp. 123-134.

Frey, J.H. and Fontana, A. (1991), "The group interview in social research", The Social Science Journal, Vol. 28 No. 2, pp. 175-187.

Grüninger, M., Atefi, K. and Fox, M.S. (2000), “Ontologies to support process integration in enterprise engineering”, Computational and Mathematical Organization Theory, Vol. 6 No. 4, pp. 381394.

Hackett, B. (2000), Beyond Knowledge Management: New ways to work and learn. The Conference Board Inc., NY.

Holsapple, C.W. and Singh, M. (2000), "Electronic commerce: from a definitional taxonomy toward a knowledge-management view", Journal of Organizational Computing and Electronic Commerce, Vol. 10 No. 3, pp. 149-170.

Holsapple, C.W. and Joshi K.D. (2003), “A KM ontology”, in Holapple C.W. (Ed.), Handbook on KM, Vol. 1 - Knowledge Matters, pp. 89-128, Springer-Verlag, Heidelberg.

Inkpen, A.C. and Dinur, A. (1998), "KM processes and international joint ventures", Organization Science, Vol. 9 No. 4, pp. 454-468.

Johannsen, F., and Fill, H. G. (2014), Codification of Knowledge in Business Process Improvement Projects, In Proceedings of the European Conference on Information Systems (ECIS), Tel Aviv, Israel, June 9-11, 2014

Kakabadse, N.K., Kakabadse, A. and Kouzmin, A. (2003), "Reviewing the KM literature: towards a taxonomy", Journal of KM, Vol. 7 No. 4, pp. 75-91.

Kamara, J.M., Anumba, C.J. and Carrillo, P.M. (2002), “A CLEVER approach to selecting a KM strategy", International Journal of Project Management, Vol. 20 No. 3, pp. 205-211.

Kanjanabootra, S., Corbitt, B. \& Nicholls, M. (2013), "Evaluating knowledge management systems efficacy and effectiveness in a design science context", Journal of Systems and Information Technology, Vol. 15, No. 4, pp. 324-46 
Kvale, S. and Brinkmann, S. (2009), Interviews: Learning the craft of qualitative research interviewing, Sage Publications, Incorporated.

Kvale, S. (2006), "Dominance through interviews and dialogues", Qualitative Inquiry, Vol. 12 No. 3 , pp. $480-500$.

Layder, D. (1998), Sociological practice: Linking theory and social research, Sage Publications, Incoporated.

Lee, C.C. and Yang, J. (2000), "Knowledge value chain”, Journal of Management Development, Vol. 19 No. 9, pp. 783-794.

Lejeune, M. (2011), "Tacit Knowledge: Revisiting the epistemology of knowledge", McGill Journal of Education, Vol. 46 No. 1, pp. 91-105.

Lin, H.F. (2007), "Knowledge sharing and firm innovation capability: an empirical study", International Journal of Manpower, Vol. 28 No. 3/4, pp. 315-332.

Madhavan, R. and Grover, R. (1998), "From Embedded Knowledge to Embodied Knowledge: New Product Development as KM", Journal of Marketing, Vol. 62 No. 4, pp. 1-12.

Maedche, A., Motik, B., Stojanovic, L., Studer, R. and Volz, R. (2003), “Ontologies for enterprise KM", Intelligent Systems, IEEE, Vol. 18 No. 2, pp. 26-33.

McDermott, R. (2000), "Why information technology inspired but cannot deliver KM", Knowledge and Communities, Vol. 41 No. 4, pp. 21-35.

McGee, T. K. (2005), "Completion of recommended WUI fire mitigation measures within urban households in Edmonton, Canada", Environmental Hazards, Vol. 6 No. 3, pp. 147-157

McNeill, I.M., Dunlop, P.D., Morrison, D.L., Skinner, T.C. (2014), "Predicting delay in residents' decision on defending versus evacuating through antecedents of decision avoidance", International Journal of Wildland Fire.

Memon, A. and Higham, P.A. (1999), “A review of the cognitive interview”, Psychology, Crime and Law, Vol. 5 No. 1-2, pp. 177-196.

Meyer, J.W. and Rowan, B. (1977), "Institutionalized organizations: Formal structure as myth and ceremony", American Journal of Sociology, pp. 340-363.

National Bushfire Warnings Taskforce (2009), Australia's Revised Arrangements for Bushfire Advice and Alerts: 2009 -2010 Fire Season.

Nesan, J. (2012), "Factors Influencing Tacit Knowledge in Construction", Australasian Journal of Construction Economics and Building, Vol. 5 No. 1, pp. 48-57.

Nonaka, I. (1994), “A dynamic theory of organizational knowledge creation”, Organization Science, Vol. 5 No. 1, pp. 14-37.

Nonaka I., Von-Krogh G. and Voelpel S., (2006), "Organizational knowledge creation theory: Evolutionary paths and future advances”, Organization Studies, Vol. 27, pp. 1179-1208.

Nonaka, I. and Toyama, R. (2003), "The knowledge-creating theory revisited: knowledge creation as a synthesizing process", KM Research and Practice, Vol. 1 No. 1, pp. 2-10.

Nonaka, I., Toyama, R. and Konno, N. (2000a), "SECI, Ba and Leadership: a Unified Model of Dynamic Knowledge Creation”, Long Range Planning, Vol. 33 No. 1, pp. 5-34.

Nonaka, I., Toyama, R. and Nagata, A. (2000b), "A firm as a knowledge-creating entity: a new perspective on the theory of the firm", Industrial and corporate change, Vol. 9 No. 1, pp. 1-20.

Noy, N. and McGuinness, D. (2001), Ontology Development 101: A Guide to Creating Your First Ontology, Technical Report SMI-2001-0880, Stamford Medical Informatics.

Nwilo, P.C. and Osanwuta, D.A. (2003), "Knowledge Sharing as a tool for Professional Development in Surveying and Geoinformatics in Nigeria", FIG Working Week, April 2003, Paris, pp. 13-17. 
O’Dell, C. and Grayson, C.J. (1998), "If only we knew what we know", California Management Review, Vol. 40 No. 3, pp. 154-174.

O'Dubhchair, K., Scott, J.K. and Johnson, T.G. (2001), "Building a knowledge infrastructure for learning communities", The Electronic Journal of Information Systems in Developing Countries, No. 4, pp. 1-21

O'Leary, D.E. (1998), “Using AI in KM: knowledge bases and ontologies”, IEEE Intelligent Systems and Their Applications, Vol. 13 No. 3, pp. 34-39.

Oliveira, M., Caldeira, M. and Batista Romão, M.J. (2012), "KM implementation: an evolutionary process in organizations", Knowledge and Process Management, Vol. 19 No. 1, pp. 17-26.

Opdenakker, R. (2006), “Advantages and Disadvantages of Four Interview Techniques in Qualitative Research”, Forum: Qualitative Social Research, Vol. 7 No. 4, Article 11.

Ordoñez, M. and Serrat, O. (2009), Disseminating knowledge products, Asian Development Bank, Washington, DC.

Polanyi, M. (1962), Personal Knowledge: Towards a Post-Critical Philosophy, University of Chicago Press, Chicago, IL.

Prior, T. and Eriksen, C. (2013), "Wildfire preparedness, community cohesion and social-ecological systems", Global Environmental Change, Vol. 23 No. 6, pp. 1575-1586.

QSR International (2013), NVivo 10, QSR International, available at http://www.qsrinternational.com (accessed November 2013).

Quintas, P., Lefrere, P. and Jones, G. (1997), “KM: a strategic agenda”, Long Range Planning, Vol. 30 No. 3, pp. 385-391.

Rhodes, A., Gilbert, J., Nelsson, C., Preece, E. (2011), Evaluation Report 2010-2011, CFA Community Safety Directorate, Melbourne, Australia.

Robinson, H.S., Anumba, C.J., Carrillo, P.M. and Al-Ghassani, A.M. (2006), "STEPS: a KM maturity roadmap for corporate sustainability”, Business Process Management Journal, Vol. 12 No. 6, pp. 793-808.

Rubenstein-Montano, B., Liebowitz, J., Buchwalter, J., McCaw, D., Newman, B. and Rebeck, K. (2001), “A systems thinking framework for KM”, Decision Support Systems, Vol. 31 No. 1, pp. 5-16.

Rumbaugh, J., Jacobson, I. and Booch, G. (1999), The unified modeling language reference manual (2nd Edition), The Addison-Wesley Object Technology Series.

Ryan, G.W., and Bernard, H.R. (2003), "Techniques to identify themes", Field methods, Vol. 15 No. 1, pp. 85-109.

Saito, A., Umemoto, K. and Ikeda, M. (2007), "A strategy-based ontology of KM technologies", Journal of KM, Vol. 11 No. 1, pp. 97-114.

Scheer, A.W. and Nüttgens, M. (2000), ARIS architecture and reference models for business process management, Springer-Verlag, Heidelberg.

Schiuma, G. (2012), "Managing knowledge for business performance improvement" Journal of KM, Vol. 16 No. 4, pp. 515-522.

Schwartz, D.G. (2006), “An Aristotelian view of KM”, Encyclopaedia of KM, Idea Group Reference, Hershey, PA (USA), pp. 10-16.

Schwandt, T.A. (1994), “Constructivist, interpretivist approaches to human inquiry”, in Denzin, N. K. and Lincoln, Y. S. (Eds.), Handbook of qualitative research, Sage, Thousand Oaks CA, pp. 118137.

Silverman, D. (2006), Interpreting qualitative data, Sage Publications, Thousand Oaks CA. 
Sims, J.H. and Baumann, D.D. (1983), Educational Programs and Human Response to Natural Hazards, Environment and Behavior, Vol. 15 No. 2, pp. 165-189

Stanford University (2009), Welcome to protégé, Stanford Center for Biomedical Informatics Research, Stanford University, viewed 19 July 2013, Retrieved from http://protege.stanford.edu/.

Vernadat, F. (2002), "UEML: towards a unified enterprise modelling language", International Journal of Production Research, Vol. 40 No. 17, pp. 4309-4321.

Von Krogh, G., Ichijo, K. and Nonaka, I. (2000), Enabling knowledge creation: How to unlock the mystery of tacit knowledge and release the power of innovation, Oxford University Press.

Von Krogh, G., Nonaka, I. and Rechsteiner, L. (2012), "Leadership in organizational knowledge creation: a review and framework", Journal of Management Studies, Vol. 49 No. 1, pp. 240277.

Von Krogh, G., Roos, J. and Slocum, K. (1994), “An Essay on Corporate Epistemology”, Strategic Management Journal, Vol. 15, pp. 53-71.

Wegmann, A., Regev, G., Garret, G.A. and Maréchal, F. (2008, September), “Specifying services for ITIL service management", Paper presented at the International Workshop on Service-Oriented Computing Consequences for Engineering Requirements (SOCCER'08), in the 16th IEEE International Requirements Engineering Conference (RE'08), Barcleona.

Weske, M. (2012), Business process management: concepts, languages, architectures, SpringerVerlag, Heidelberg. 